\title{
AVALIAÇÃO DOS CRITÉRIOS DE SELEÇÃO DE TRANSPORTADOR E MODAIS PARA O ESCOAMENTO DA SAFRA DE SOJA BRASILEIRA
}

\author{
M.S.Oliveira Neto ${ }^{1}$; A.C.Reis ${ }^{2 *}$; G.H.C.Stender ${ }^{2}$; W.O.Costa ${ }^{3}$; C.G.Souza ${ }^{2}$ \\ 1 Pontifícia Universidade Católica do Rio de Janeiro, 22451-900, Rio de Janeiro-RJ, Brasil \\ 2 Centro Federal de Educação Tecnológica Celso Suckow da Fonseca, 20271-110, Rio de Janeiro-RJ, Brasil \\ 3 Universidade do Estado do Rio de Janeiro, 20550-900, Rio de Janeiro-RJ, Brasil \\ * acreis_1@yahoo.com.br
}

\section{RESUMO}

A presente pesquisa se propõe a identificar e analisar os principais critérios que auxiliam o embarcador quanto à seleção do transportador e o modal a ser utilizado no escoamento da safra agrícola e de seus derivados. Através da utilização do método AHP, que é uma ferramenta auxiliadora à tomada de decisão a partir da análise multicritério de variáveis, foi possível demonstrar os resultados obtidos, avaliando os critérios identificados e analisando-os com a profundidade a qual a ferramenta proporciona. Assim, é possível identificar a necessidade iminente de se desenvolver corredores de exportação a partir das principais áreas produtoras de soja, onde foi considerado que o modo de transporte está sempre disponível. A combinação entre os modais hidroviário e ferroviário é fundamental para que os critérios de menor custo total, transit time e questões qualitativas sejam atendidas.

PALAVRAS-CHAVE: Agronegócio; estrutura logística; modal; método AHP.

\section{STOCK MANAGEMENT AND VENDOR MANAGED INVENTORY: A CASE STUDY IN A SUPERMARKET NETWORK}

\begin{abstract}
This research aims to identify and analyze the main criteria that help the shipper to choose the carrier and the modal to be used to transport the harvest and its derivatives. Ultimately, the results obtained will be

demonstrated through criteria identified and analyzed consistently through the AHP method, which is a multicriteria decision-making method that aids decision making by taking into account all the variables analyzed.
\end{abstract}

KEYWORDS: agribusiness; logistics structure; modal; AHP method. 


\section{INTRODUÇÃO}

O Brasil é um país de dimensões continentais, com 8.514.876,60 km² (IBGE, 2013), esta característica traz consigo inúmeras vantagens e desvantagens. Uma destas é a dificuldade para o escoamento de suas safras, pois carece de infraestrutura adequada para suportar o trânsito da safra agrícola para exportação e abastecimento do mercado interno, estimada em 202,23 milhões de toneladas para o período 2014/2015 (CONAB, 2015).

Moreira Neto (2015) define que diversas restrições são impostas ao cliente e ao operador logístico na realização do escoamento da safra do campo ao porto, dentre elas a falta de infraestrutura adequada, congestionamentos nos acessos rodoviário e ferroviário no descarregamento e marítimo no período de atracação para carregamento, esteiras e carregadores de navios obsoletos para o carregamento e descarregamento das cargas. Além destes itens destacados, há também problemas quanto a baixa quantidade de silos e pouca capacidade de armazenagem.

As regiões Centro-Oeste e Sul são as principais produtoras de soja do país, correspondendo a aproximadamente $75 \%$ de toda a produção de soja do país, levando-se em consideração as médias de 2007 a 2013 (SALIN, 2014). Contudo, o cenário entre as duas regiões é muito diferente, enquanto a região Sul possui maior concentração de malha ferroviária que a região Centro-Oeste, isto traz à tona a necessidade de se adequar e planejar a infraestrutura viária de acordo com a capacidade produtiva para elaborar o melhor meio de escoar a safra (CORREA; RAMOS, 2010).

Branco et al. (2012) ressaltam que é preciso levar em consideração os transportadores e embarcadores, pois conhecem as restrições e muitos pontos de melhoria que podem ser implementados. Com isso, elaborar um plano de melhoria que busque encontrar e analisar as melhores formas para futuros investimentos em busca da multimodalidade que permite a redução dos custos logísticos. No contexto científico e tecnológico, o presente estudo verifica a importância de utilizar-se da experiência prático-teórica para estabelecer um modelo de avaliação de desempenho de todo o conjunto do agronegócio de grãos, da origem aos portos. Assim, a proposta deste trabalho busca identificar os principais critérios que auxiliam o embarcador na seleção da melhor opção de conjunto transportador / modo de transporte disponível, de forma a atender a necessidade de escoamento da carga com as opções disponíveis nos corredores apresentados.

Esta pesquisa foi realizada com base nas informações cedidas através de entrevistas dos profissionais das áreas de logística, responsáveis pela seleção e contratação de transportadoras e de operadores logísticos das duas principais empresas do agronegócio brasileiro, que neste artigo serão representadas como empresa 1 e empresa 2, devido a confidencialidade solicitada.

Assim, o presente artigo é composto de contextualização sobre o agronegócio e o mercado de soja. Posteriormente, é realizada uma revisão na literatura acadêmica de forma a embasar conceitualmente este artigo. Em seguida a metodologia é descrita de forma que este trabalho possa ser replicado. Logo após é descrito o estudo de caso. Por fim, a conclusão da análise que evidencia a necessidade de utilização de um modelo de seleção do modo de transporte para que haja a garantia da melhor estratégia logística.

\section{REVISÃO DA LITERATURA}

\subsection{Mercado da soja}

As principais empresas do agronegócio brasileiro, juntas representam mais de $60 \%$ de participação do mercado de soja, fato que se reflete também nos seus níveis de exportação e influência no PIB do país, correspondendo a 23\%. Com a evolução da produção brasileira de soja 
que se tornou a segunda maior do planeta, atrás somente dos EUA, devido a alta demanda pela exportação do grão, principalmente para a China, onde, em 2013, 80\% de toda a soja importada por eles chineses era oriunda dos campos brasileiros (MOTA et al., 2014).

Mas como fator identificado com o aumento da produção, de acordo com a figura 2, a produção da soja encontra-se cada vez mais distante dos grandes centros consumidores internos e dos tradicionais portos exportadores do produto, que estão concentrados na região Sul e Sudeste, notoriamente Paranaguá e Santos, respectivamente. Assim, os custos relativos à movimentação destes grãos aos portos são a grande oportunidade de alcançar o diferencial competitivo pelos agentes deste mercado. Com isso, através de uma reformulação das rotas de exportação, de modo que sejam melhor aproveitados os portos das regiões Norte e Nordeste, tornando viável a infraestrutura para se chegar a eles e reduzir os custos de movimentação, gerando atratividade maior para a nova rota (SOUZA, 2012 apud MOREIRA et al., 2013).

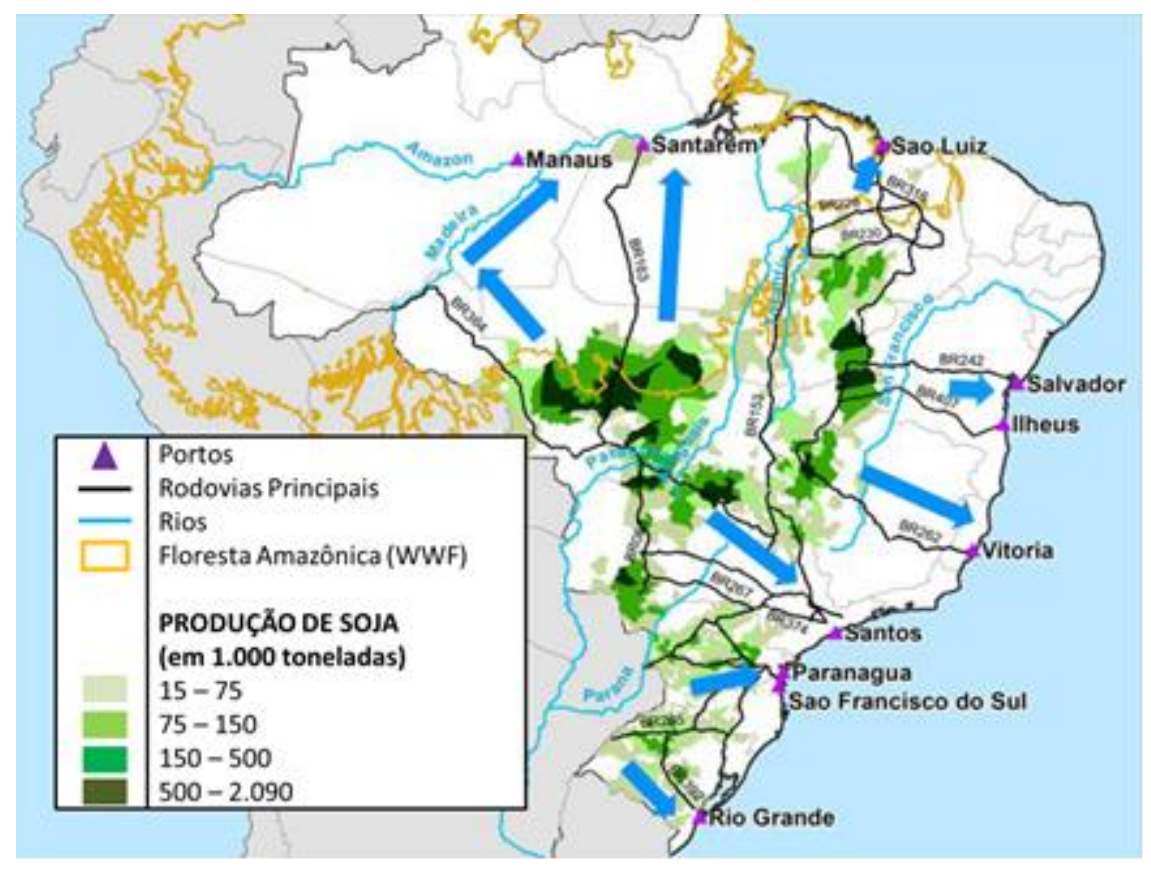

Figura 2: Principais rotas de escoamento da soja no Brasil.

Fonte: SALIN (2014).

O volume de produção de soja no Brasil entre os anos de 2001 e 2014, conforme tabela 1, demonstra o aumento significativo na produção brasileira, com crescimento de aproximadamente 4\% no comparativo dos anos de 2013 e 2014. A média de exportações (29.211 em 1.000 toneladas) foi ultrapassada a partir do ano de 2010 a 2014 em 37,29\% ao ano. Assim, há a necessidade de se dar a devida importância e atenção ao desenvolvimento dos corredores de exportação de modo a suportar o escoamento a safra e os produtos agrícolas brasileiros para o mercado externo (SALIN, 2014).

Tabela 1- Brasil: Produção de grãos, distribuição e suprimento de soja período 2001 a 2014.

\begin{tabular}{|c|c|c|c|c|c|c|}
\hline no* & Produção & $\begin{array}{c}\text { Importação }+ \\
\text { Estoque Inicial }\end{array}$ & Suprimento Total & Exportação & Esmagamento & Consumo Doméstico \\
\hline 001 & 43.500 & $1.100+657$ & 45.257 & 16.074 & 25.842 & 28.202 \\
\hline 002 & 52.000 & $1.124+981$ & 54.105 & 19.987 & 27.796 & 30.220 \\
\hline
\end{tabular}




\begin{tabular}{|c|c|c|c|c|c|c|}
\hline 003 & 51.000 & $364+3.898$ & 55.262 & 19.257 & 28.914 & 31.457 \\
\hline 004 & 53.000 & $352+4.548$ & 57.900 & 22.799 & 29.728 & 32.413 \\
\hline 005 & 57.000 & $40+2.688$ & 59.728 & 24.770 & 28.756 & 31.506 \\
\hline 006 & 59.000 & $108+3.452$ & 62.560 & 23.805 & 31.511 & 34.261 \\
\hline 007 & 61.000 & $83+4.494$ & 65.577 & 24.515 & 31.895 & 33.579 \\
\hline 008 & 57.800 & $124+6.367$ & 64.291 & 28.041 & 30.779 & 38.550 \\
\hline 009 & 69.000 & $150+2.671$ & 71.821 & 29.188 & 35.700 & 40.164 \\
\hline 010 & 75.300 & $40+4.083$ & 79.423 & 33.789 & 37.264 & 39.130 \\
\hline 011 & 66.500 & $298+5.470$ & 72.268 & 31.905 & 36.230 & 39.338 \\
\hline 012 & 82.000 & $240+1.233$ & 83.473 & 42.826 & 36.388 & 39.975 \\
\hline 013 & 87.500 & $550+1.309$ & 89.359 & 45.500 & 37.000 & 40.200 \\
\hline 014 & 91.000 & $500+3.884$ & 95.384 & 46.500 & 37.200 & \\
\hline
\end{tabular}

* Valores em 1.000 toneladas

Fonte: SALIN (2014) com adaptações do autor.

O Brasil é o segundo maior produtor mundial de soja, tal cultura vem expandindo sua área de ocupação em média 5\% ao ano. Isto possibilitou que a safra brasileira ficasse mais próxima em números totais dos EUA, maior produtor mundial do grão, a diferença entre os níveis de produção é de 7.929 mil toneladas. A tabela 2 demonstra a evolução desde o ano de 2009 dos principais produtores mundiais do grão.

Tabela 2- Mundo - Produção de soja mundial de 2009 a 2014.

\begin{tabular}{|l|l|l|l|l|l|l|}
\hline PAÍ́* & $\mathbf{2 0 0 9}$ & $\mathbf{2 0 1 0}$ & $\mathbf{2 0 1 1}$ & $\mathbf{2 0 1 2}$ & $\mathbf{2 0 1 3}$ & $\mathbf{2 0 1 4}$ \\
\hline EUA & 90.605 & 84.192 & 82.561 & 89.507 & 98.929 & 98.929 \\
\hline Brasil & 75.300 & 66.500 & 82.000 & 87.500 & 91.000 & 91.000 \\
\hline Argentina & 49.000 & 40.100 & 49.300 & 54.000 & 54.000 & 54.000 \\
\hline China & 15.080 & 14.485 & 13.050 & 12.200 & 12.000 & 12.000 \\
\hline Índia & 9.800 & 11.000 & 11.500 & 11.000 & 12.000 & 12.000 \\
\hline Paraguai & 7.128 & 4.043 & 8.300 & 8.100 & 8.200 & 8.200 \\
\hline Canadá & 4.445 & 4.298 & 5.086 & 5.200 & 6.100 & 6.100 \\
\hline Outros & 12.787 & 14.907 & 16.056 & 16.281 & 17.766 & 17.591 \\
\hline TOTAL & $\mathbf{2 6 4 . 1 4 5}$ & $\mathbf{2 3 9 . 5 2 5}$ & $\mathbf{2 6 7 . 8 5 3}$ & $\mathbf{2 8 3 . 7 8 8}$ & $\mathbf{2 9 9 . 9 9 5}$ & $\mathbf{2 9 9 . 8 2 0}$ \\
\hline
\end{tabular}

Fonte: SALIN (2014).

Por fim, pode-se perceber que há evolução nos níveis de exportação brasileiros, cerca de $1,09 \%$ ao ano, fato que justifica o estudo do sistema de transporte brasileiro, de modo a levantar 
questionamentos quanto ao desenvolvimento de um sistema de escolha dos modais adequados para elevar a lucratividade e minimizar os riscos do processo logístico no escoamento da safra brasileira.

\subsection{Sistemas de transporte}

\subsubsection{Rodoviário}

Wanke et al. (2014) destaca que a integração das regiões brasileiras foi realizada sob a ótica da construção de rodovias, e a utilização de outros modais foi postergada, a espera de projetos específicos para hidrovias e ferrovias. Isto traz a tona uma realidade completamente controversa face aos países desenvolvidos, no Brasil o modal rodoviário corresponde a aproximadamente $60 \%$ de todo transporte de granéis do país. A utilização do modal rodoviário para o transporte de cargas é o que mais influencia o custo logístico total, devido aos diversos custos diretos e indiretos relacionados como o custo por km rodado, seguro de cargas, perdas de trajeto, entre outros aspectos (BRAVO; VIDAL, 2013).

Uma infraestrutura básica para operacionalizar a distribuição da safra pelo país depende de uma rede complexa composta por hidrovias, ferrovias, rodovias, silos, áreas de transbordo, portos e armazéns. Porém, o cenário brasileiro não atende a estes pré-requisitos, o que traz enormes dificuldades para o transporte, dentre eles a má conservação das rodovias, consideradas como ruim ou muito ruim por 28,53\% dos transportadores de carga no triênio 2011-2013 (SALIN, 2014), conforme figura 1 , ferrovias com trechos abandonados, portos com restrição de calado, pouca quantidade de berços e retroárea reduzida para o volume atual de operações portuárias (DE LIMA; BUENO, 2013).

\section{CONDIÇÕES DAS RODOVIAS BRASILEIRAS}

$2011-2013$

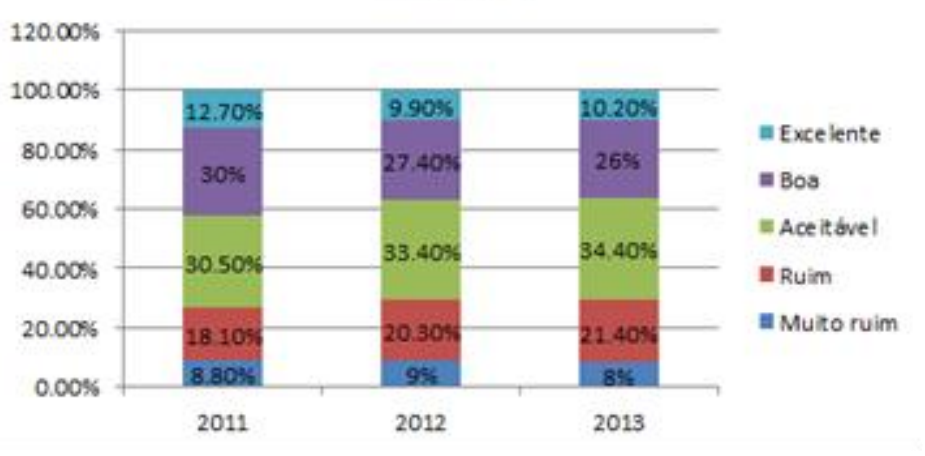

Figura 1: Condições das rodovias brasileiras.

Fonte: SALIN (2014).

Steadieseifi et al. (2014) defende que o transporte rodoviário é um dos mais utilizados no mundo devido a sua facilidade de locomoção do ponto de partida ao ponto de destino, mas com a crise mundial enfrentada em 2008, muitos ramos de produção tiveram de se adaptar a uma nova realidade, na qual há a necessidade tangente de se reduzir custos e elevar a eficiência, isto acaba pressionando todo o processo logístico a obter alternativas mais eficazes com menor custo total.

Demir et al. (2015) e De Souza (2013) revelam que o transporte rodoviário quando mal dimensionado pode trazer inúmeros malefícios à população, como exemplos podem ser descritos a grande emissão de gás carbônico, o aumento dos congestionamentos, acidentes, entre outros. MesaArango e Ukkusuri (2013), por outro lado, destacam como vantagens deste modal a capacidade de 
movimentação, facilidade de transbordo para veículos menores e ser o economicamente mais viável para curtas e até médias distâncias.

Quadros e Nassi (2015) citam que o transporte rodoviário é fundamental no mix logístico e que sua utilização inclui diversos benefícios e malefícios inerentes a sua escolha, contudo os malefícios podem e devem ser minimizados com o desenvolvimento de projetos de infraestrutura logística baseados no melhor escoamento da produção pelas vias existentes e o estudo profundo da criação de novas vias que beneficiem, principalmente, o transporte de carga para que não seja sobrecarregada a malha existente.

\subsubsection{Ferroviário}

Da Silva e Marujo (2012) corroboram que para o transporte de cargas, o modal ferroviário é o segundo mais utilizado no Brasil, e transporta aproximadamente 460 milhões de toneladas anualmente. O Ministério dos Transportes destaca que o modal ferroviário no Brasil é responsável pelo transporte de mercadorias de baixo valor agregado como as commodities (BIT, 2015).

Dulac (2013) relata que o transporte ferroviário teve perdas significativas no que tange sua extensão, com redução da sua quilometragem em trilhos desde o ano $2000 \mathrm{em}$ detrimento do uso de rodovias. Na última década, ao menos $66.000 \mathrm{~km}$ da malha ferroviária foi removido ou desativado. A malha ferroviária brasileira, concentrada nas regiões Sul, Sudeste e Nordeste, conforme é possível observar na figura 3, a qual grande parte fora construída no início do século passado, totalizando $28.366 \mathrm{~km}$ (ANTF, 2014).

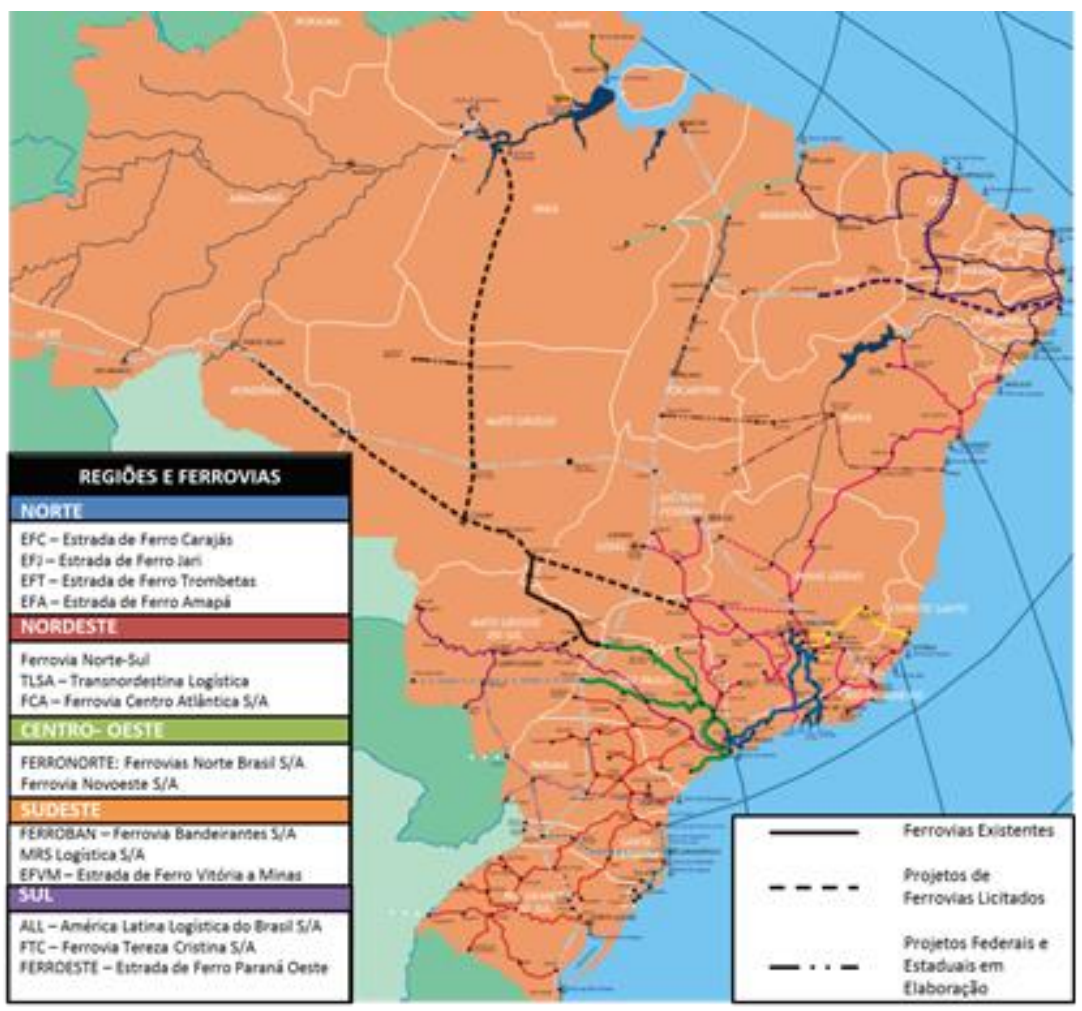

Figura 3- Mapa do Sistema Ferroviário Nacional.

Fonte: SALIN (2014).

Vilaça (2012) e Alves et al. (2012) defendem que o Brasil tem adotado uma política de infraestrutura de transportes incoerente com suas dimensões, pois países com características semelhantes como China, EUA, Canadá e Rússia tem seu transporte de cargas realizado pelo modal ferroviário numa faixa que varia de $40 \%$ a $60 \%$ de tudo o que é transportado. Por sua vez, o Brasil 
registra somente $25 \%$ na utilização deste modal. O modelo de transporte, rodoviário, é um dos principais contribuintes com a elevação do Custo Brasil, o que reflete na competitividade dos produtos brasileiros, enquanto o custo da utilização do transporte ferroviário é de $17,6 \%$ em relação ao custo total do transporte rodoviário.

O modelo de transporte ferroviário caracteriza-se, especialmente, por sua capacidade de transportar grandes volumes com elevada eficiência energética, principalmente em casos de deslocamentos a médias e longas distâncias (BOZOKY et al., 2014). Além disso, apresenta, maior segurança em relação ao modelo rodoviário, com menor índice de acidentes e menor incidência de perdas, furtos e roubos (BIT, 2015).

Outro fator que deve ser levado em consideração é a interiorização da produção agrícola, vide figura 2 para o exemplo da soja, que aumentou em 14\% a distância das viagens para entrega das cargas (VILAÇA, 2012). Somado a isso, deve-se considerar como fatores para a pouca eficiência do transporte ferroviário brasileiro a baixa velocidade de viagem com pouca ou inexistente integração com os demais modais (DA SILVA; MARUJO, 2012).

É possível observar que o modal ferroviário no país é pouco explorado, sendo até subutilizado em diversas regiões do país, principalmente em regiões mais distantes dos grandes centros urbanos. Contudo, este modal é tido como ideal por muitos pesquisadores, sua total eficiência é alcançada através do desenvolvimento de planos de integração com os modais rodoviário e ferroviário, permitindo agilidade no escoamento de agronegócio do campo ao porto (ALVES et al., 2012).

\subsubsection{Hidroviário}

Atualmente, o transporte hidroviário brasileiro conta com aproximadamente 13 mil quilômetros de hidrovias navegáveis, contudo devido ao grande potencial hídrico brasileiro, a malha poderia, com os investimentos corretos, chegar até 63 mil quilômetros considerando rios e áreas superficiais fluvio-lacustres (DE LIMA; BUENO, 2013). Saraiva e Maehler (2013) destacam o transporte hidroviário pelo baixo custo total, devido as grandes distâncias percorridas que diluem os custos no trajeto, somado a isso está na grande capacidade de carga das embarcações.

O Ministério dos Transportes ressalta a importância do modal hidroviário, principalmente, no deslocamento de produtos não perecíveis como minérios, cascalhos, areia, carvão, ferro e grãos. Dentre as principais vantagens deste transporte estão a grande capacidade de carga, baixo custo de transporte e manutenção, por outro lado, as desvantagens são a baixa velocidade de transporte, pouca flexibilidade, altamente influenciado pelas condições climáticas (BIT, 2015).

\subsubsection{Intermodal}

Santos et al. (2013) relata que apesar de o agronegócio brasileiro vir superando seus recordes produtivos safra a safra, ainda há enorme dificuldade com relação ao transporte logístico, fator que minimiza os lucros do processo. Neste contexto, a intermodalidade surge como opção para redução dos custos logísticos, com isso o agente intermodal torna-se elo chave no sucesso desta operação, pois sua eficiência que determinará a vantagem competitiva. Braga e Castillo (2014) destacam que a elaboração de nós logísticos para a mudança do modal de transporte é realizada levando-se em consideração aspectos geopolíticos e geoeconômicos. Conforme figura 4, com a desigualdade na distribuição espacial dos pontos de transferências de cargas criam-se pontos de alta 
densidade e de baixa densidade para realização do transbordo. E demonstra a convergência do sistema logístico brasileiro rumo a uma mesma região, o que sobrecarrega a malha existente.

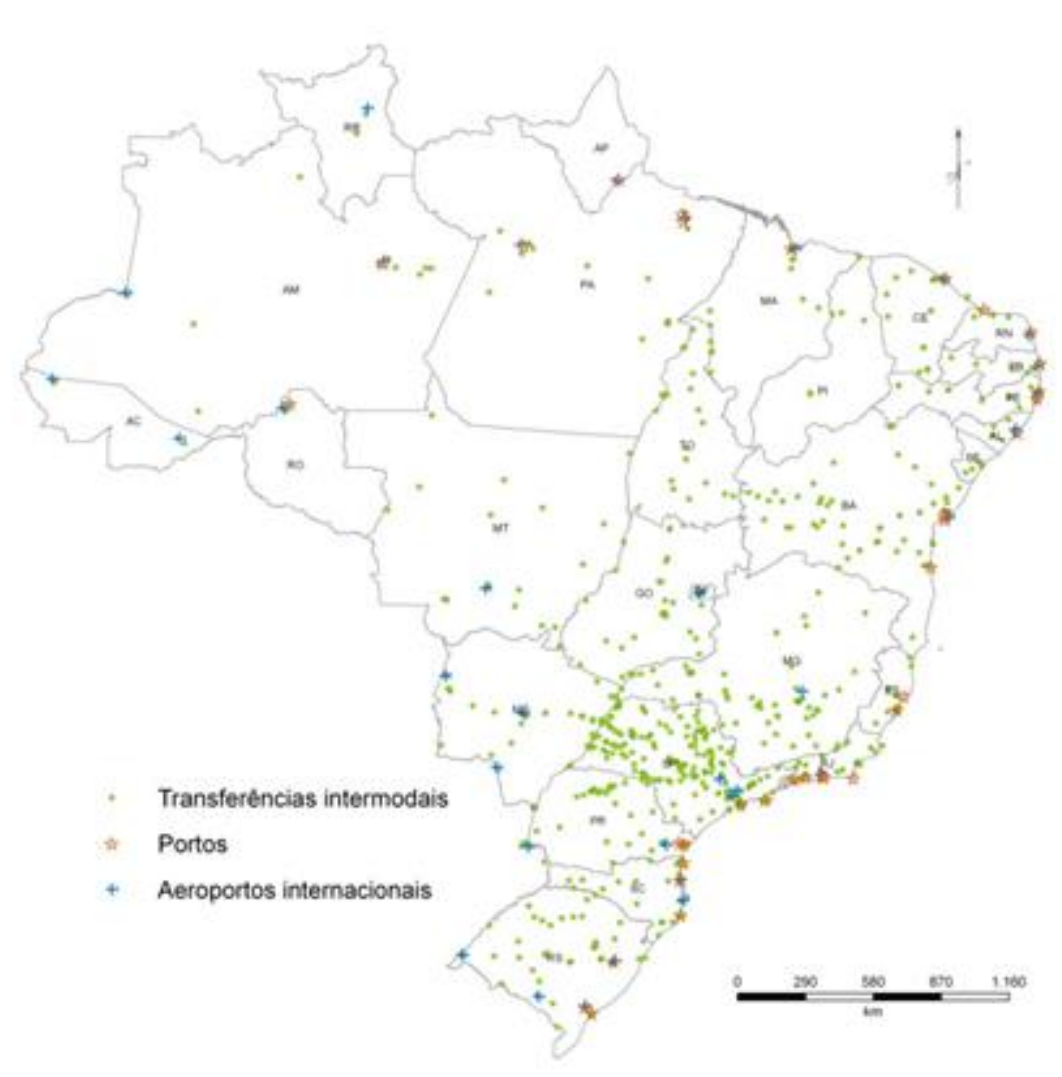

Figura 4- Mapa dos nós logísticos brasileiros.

Fonte: BRAGA \& CASTILLO (2014).

A importância do desenvolvimento da intermodalidade vem ganhando cada vez mais destaque no cenário nacional, com o desenvolvimento de pesquisas focadas na intermodalidade e a criação de terminais intermodais. Este estudo busca integrar os modais de forma a mitigar as desvantagens de cada modal, mas para que isso aconteça é imprescindível a realização de investimentos para desenvolver a estrutura física adequada através de terminais intermodais (SANTOS et al., 2013).

\subsection{Método AHP}

Desenvolvido na década de 1970, pelo professor Thomas L. Saaty, o método AHP (Analytic Hierarchy Process) consiste em dividir o problema de decisão nos mais variados níveis hierárquico. No nível mais alto concentra-se o problema a ser solucionado, nos níveis intermediários ficam os fatores que irão influenciar a tomada de decisão final. No nível mais baixo encontram-se as alternativas ao problema decisório, assim os elementos desse processo hierárquico são comparados uns com os outros (TINOCO et al., 2013).

Alves e Alves (2015) definem o método AHP como de decisão com múltiplos critérios ou objetivos, tal técnica possui grande abrangência de áreas de aplicação, tendo relatos de utilização na educação, medicina, agrícola, pública, além da industrial e de engenharia. O AHP busca demonstrar a melhor orientação de tomada de decisão baseada na prioridade para os múltiplos critérios definidos, outro fator que vale ser destacado é a possibilidade em se avaliar dados quantitativos e 
qualitativos com graus de certeza e incerteza.

Após a definição da estrutura do problema com a elaboração do objetivo, critérios e alternativas, o tomador de decisão passa à fase seguinte do método AHP, onde se fazem as comparações entre elementos, gerando as chamadas matrizes de comparação ou de julgamento, quando é gerada uma matriz de avaliação $\mathbf{n}$ X $\mathbf{n}$, onde $\mathbf{n}$ é o número de alternativas, com valores de comparação $\mathbf{r}_{\mathbf{i j}}$, e onde se compara a alternativa $\mathbf{i}$ com a $\mathbf{j}$ (TINOCO et al., 2013).

O método AHP visa converter os critérios em valores, de forma que, com o uso de graus, possam ser processados e comparados, permitindo que elementos imensuráveis sejam comparados, auxiliando a tomada de decisão para a obtenção do objetivo principal. O professor Saaty estabeleceu uma escala absoluta para fazer comparações entre os critérios, comparando o primeiro com um segundo e dizendo o quanto um é mais ou menos importante que o segundo (GRANEMANN; FIGUEIREDO, 2013). Usa-se uma escala de 1 a 9 - tabela 3 - estabelecendo significados para cada um dos índices ímpares Para as situações intermediárias estabelecidas na tabela, utiliza-se valores pares de 2 a 8 .

Tabela 3- Representação numérica das comparações.

\begin{tabular}{|l|c|l|}
\hline \multicolumn{2}{|c|}{ GRAU } & \multicolumn{1}{c|}{ DESCRIÇÃO } \\
\hline Igual importância & 1 & As duas atividades contribuem igualmente para o objetivo. \\
\hline Moderadamente mais importante & 3 & $\begin{array}{l}\text { Importância pequena de uma sobre outra - A experiência e o } \\
\text { julgamento favorecem levemente uma atividade em relação à outra. }\end{array}$ \\
\hline Fortemente mais importante & 5 & $\begin{array}{l}\text { Importância grande ou essencial - A experiência e o julgamento } \\
\text { favorecem fortemente uma atividade em relação à outra. }\end{array}$ \\
\hline Muito fortemente mais importante & 7 & $\begin{array}{l}\text { Importância muito grande ou demonstrada - Uma atividade é } \\
\text { muito fortemente favorecida em relação à outra, sua dominação de } \\
\text { importância é demonstrada na prática. }\end{array}$ \\
\hline Extremamente mais importante & 9 & $\begin{array}{l}\text { Importância absoluta - A evidência favorece uma atividade em } \\
\text { relação à outra com o mais alto grau de certeza. }\end{array}$ \\
\hline
\end{tabular}

Fonte: GRANEMANN \& FIGUEIREDO (2013).

TINOCO et al. (2013) utilizou o método AHP juntamente ao MIP-Mixed Integer Linear Programing, encontrando os cinco mais importantes atributos do transporte considerados pelo principais transportadores. São eles: habilidade em condições adversas, adequação estratégica, flexibilidade, melhoria continua e qualidade. Aharonovitz e Vieira (2014), analisando a seleção de serviços logísticos adotam para a seleção de transportador os seguintes atributos como os cinco mais importantes: tempo de trânsito confiável, custos de transporte, tempo total de trânsito, flexibilidade nas negociações e estabilidade financeira.

\subsection{Critérios de seleção de frete e modo de transporte}

No desenvolvimento do método de auxílio à decisão para a seleção do frete e modo de transporte, foi construída uma árvore de decisão, através de um método quantitativo que auxilia a verificar a aderência dos critérios com o conceito aplicado, adotando o método AHP. Tal método, além de fornecer o peso de cada critério, fornece a inconsistência das escolhas, possibilitando verificar de forma quantitativa se as escolhas estão ou não aderentes ao objetivo da empresa (ALVES; ALVES, 2015).

No desenvolvimento desta proposta, os critérios Custo Total - CT (todos os custos envolvidos na contratação do frete - taxas, tarifas, pedágios, frete, seguro, dentre outras - bem como o custo de estoque relativo à carga transportada), Transit Time - TT (tempo de transporte despendido do ponto $\mathrm{A}$ ao $\mathrm{B}$, não considerando os tempos de transbordo, com a confiabilidade na garantia do cumprimento do prazo) e Questões Qualitativas - QQ (itens subjetivos como integridade da carga, risco, e outros), validados junto aos interlocutores nas entrevistas realizadas. 
Inicialmente elaborou-se um questionário semiestruturado útil para conduzir a entrevista, identificando os efetivos critérios adotados. Como seleção do embarcador a ser entrevistado, optouse pelas duas principais empresas do agronegócio brasileiro que juntas, projetam um movimento de mais de $60 \%$ da soja brasileira (CONAB, 2015).

Critérios são os argumentos que auxiliam o embarcador a realizar a escolha do melhor conjunto transportador / modo de transporte. O embarcador seleciona a melhor opção basicamente avaliando custo, ou seja, mais especificamente o preço de frete estabelecido para a carga a ser transportada, no trecho origem-destino predefinido. Considera também uma variedade de fatores, como tempo de transporte, multimodalidade, contratos, distância, segurança, integridade, agilidade, urgência, etc.

\section{MATERIAIS E MÉTODOS}

O operador do agronegócio brasileiro ao escoar as cargas ao longo da cadeia de suprimentos, deve levar em consideração as seguintes restrições: despesa com frete, tempo em trânsito e capacidade do modo de transporte escolhido, além de outros fatores. A equalização destas restrições busca atender a sua necessidade operacional e financeira, assim preocupa-se em uma análise multicritérios, onde são consideradas todas as restrições mencionadas em busca do conjunto que melhor atenda o conjunto transportador / modo de transporte.

Assim, para a pesquisa foi proposto o desenvolvimento de um estudo de caso, baseado nas principais experiências das duas maiores empresas do agronegócio brasileiro, em participação de mercado. Os dados foram colhidos através de entrevistas abertas com os gerentes de logística e analisados mediante aos pontos chave para o sucesso da proposta através do método AHP. Portanto, para delimitar o desenvolvimento do estudo, tem-se como suporte inicial revisão bibliográfica de literatura acadêmica básica, sobre o tema de interesse, na expectativa de encontrar modelos desenvolvidos e aplicabilidade do conceito proposto. Assim, desenvolvendo o estudo de caso baseado nos conceitos acadêmicos estudados na revisão bibliográfica.

O trabalho em questão ilustra a confiabilidade do método no auxílio para a caracterização e estruturação dos critérios para a seleção de transportadora e/ou operador logístico. Em um cenário com a introdução de técnicas de produção, como o just in time (JIT), onde busca-se operar com níveis mínimos de estoque e racionalização máxima dos recursos, é fundamental a boa seleção do prestador de serviço de transporte de carga que garanta confiabilidade na entrega da carga a tempo e à hora (WALTER; TUBINO, 2013).

Aharonovitz e Vieira (2014) destacam a importância do uso do método AHP para auxiliar na avaliação do transporte intermodal que atende o escoamento de carga, determinando a rota e modo de transporte mais adequado aos importadores da região, levando em consideração fatores que às vezes são deixados de lado, mas é tão importante quanto o custo, partes vitais na estratégia logística. Confrontado com o método como o DQDA - Dual Questioning Determinante Atribute, o AHP é apresentado como ferramenta no auxílio para a escolha do modo de transporte e rota para atender ao escoamento da carga em questão (KAKAR et al., 2013).

No presente estudo, propõe-se a utilização do método AHP para auxiliar a seleção e classificação dos critérios que interferem a tomada de decisão do responsável pela escolha do transportador / modo de transporte. Assim, o método consiste na tomada de decisão a partir de um objetivo estabelecido. No caso estudado, analisa-se a seleção do conjunto transportador / modo de transporte. Portanto, identificando os critérios que interferem e auxiliam na tomada de decisão de escolha deste conjunto. 


\section{RESULTADOS E DISCUSSÃO}

Neste tópico serão identificados, avaliados e classificados os critérios estabelecidos nas entrevistas realizadas com os embarcadores, gestores e contratantes do serviço de transporte de empresas do agronegócio pesquisadas, Empresa 1 e Empresa 2, com expressão no cenário nacional e internacional, verificando a aderência de seus argumentos com a aplicação do método AHP. As entrevistas permitiram coletar sólido material e diversas observações em que destacam sugestões de critérios, distintamente por empresa, para a contratação do conjunto transportador/modo de transporte. A tabela 4 apresenta os critérios sugeridos nas entrevistas.

Tabela 4- Critérios sugeridos.

\begin{tabular}{|c|c|}
\hline \multicolumn{2}{|c|}{ CRITÉRIOS SUGERIDOS } \\
\hline EMPRESA 1 & EMPRESA 2 \\
\hline $\begin{array}{ll}\text { - } & \text { Custo Total } \\
\text { - } & \text { Tempo } \\
\text { - } & \text { Urgência } \\
\text { - } & \text { Intermodalidade } \\
\text { - } & \text { Contrato } \\
\text { - } & \text { Integridade } \\
\text { - } & \text { - Segurança } \\
\text { - } & \text { Distância } \\
\text { - } & \text { Agilidade }\end{array}$ & $\begin{array}{ll}\text { - } & \text { Custo } \\
\text { - } & \text { Transit time } \\
\text { - } & \text { Urgência } \\
\text { - } & \text { Intermodalidade } \\
\text { - } & \text { Contrato } \\
\text { - } & \text { Perdas } \\
\text { - } & \text { Sinistro } \\
\text { - } & \text { Confiabilidade } \\
\text { - } & \text { Capacidade } \\
\text { - Flexibilidade } \\
\text { - }\end{array}$ \\
\hline
\end{tabular}

\subsection{Análise}

Assim, de posse das entrevistas das empresas 1 e 2, foi possível estabelecer o nível um da árvore hierárquica como pode ser observado na tabela 5.

Tabela 5- Objetivo Geral - Nível 1.

\begin{tabular}{|c|}
\hline OBJETIVO GERAL \\
\hline Contratação do conjunto transportador/modo de transporte adequado \\
\hline
\end{tabular}

$\mathrm{O}$ ato de contratar um conjunto transportador / modo de transporte é considerar o fato de um modo de transporte atender a necessidade do embarcador de escoar sua carga respeitando um conjunto de critérios previamente definidos. Estabeleceu-se a premissa que todos os modos de transporte estão acessíveis quando se faz necessária a contratação de transporte para o escoamento da carga. Então, para o nível 2, têm-se como critérios os itens relacionados na tabela 6:

Tabela 6- Critérios ou Atributos - Nível 2.

\begin{tabular}{|c|c|c|}
\hline \multicolumn{3}{|c|}{ CRITÉRIOS OU ATRIBUTOS } \\
\hline Custo Total & Transit Time & Questões Qualitativas \\
\hline
\end{tabular}

Os critérios apresentados na tabela 6 são aqueles que influenciam diretamente o embarcador na tomada de decisão para a seleção e contratação do conjunto transportador / modo de transporte, seu objetivo geral. Para o nível 3 têm-se as alternativas ou subcritérios que compõem estes critérios, podendo chegar-se a um quarto nível de alternativas.

Para o critério Custo Total têm-se os seguintes componentes no nível 3: 

- Custo de Frete
Custo de frete com taxas, impostos, ad valorem, pedágios e outros.
- Custo de Inventário
Custo de estoque imposto em virtude da carga em trânsito.

Para o critério Transit Time têm-se os seguintes componentes no nível 3:
- Número de Dias
- Variabilidade
Tempo despendido no transporte da carga no trajeto origem-destino desconsiderando a operação de carga em sua origem e destino.
Certeza da entrega da carga no prazo previsto.

Para o critério Questões Qualitativas têm-se os seguintes componentes, atingindo o nível 3, conforme tabela 7:

Tabela 7- Questões Qualitativas - Nível 3.

\begin{tabular}{|c|c|c|}
\hline \multicolumn{3}{|c|}{ QUESTÕES QUALITATIVAS } \\
\hline Serviço ao Cliente & Capacidade de Transporte & Monitoramento \\
\hline
\end{tabular}

Para o Serviço ao Cliente têm-se os seguintes componentes no nível 4:

- Comunicação

- Soluções dos Problemas

- Tempo de Resposta

- Confiabilidade e Risco

- Acuracidade na Fatura
Comunicação ágil entre contratante e transportadora, utilizando-se do uso de meio eletrônico (EDI).

Equacionamento dos problemas existentes, como reposição de veículo, plano de ação para atrasos, perdas e avarias.

Influência dos contratos no cumprimento da tarefa do transporte quanto a limitação de carga, disponibilidade de veículos, horários, frequência.

Integridade e segurança da carga com medidas de prevenção e combate ao furto.

Precisão, clareza, disponibilidade de documentos fiscais e contábeis.

Para a Capacidade de Transporte têm-se os seguintes componentes no nível 4:

- Contratos

- Disponibilidade

- Atendimento no Pico
Influência do contrato no cumprimento do transporte quanto a limitação de carga, carga mínima, disponibilidade de veículos, horários e frequência.

Oferta do modo de transporte escolhido sempre disponível no momento de atendimento à demanda.

Capacidade de atender a imprevistos.

Para Monitoramento têm-se os seguintes componentes no nível 4:

- Tempo de Resposta

- Cobertura

-Acuracidade
Adoção de equipamentos com georreferenciamento.

Atendimento a toda a área de atuação.

Qualidade e precisão da informação disponibilizada.

Chega-se à árvore hierárquica estabelecida para o estudo de caso em questão onde será analisado até o nível dois para a aplicação do método AHP, focando os critérios Custo Total e Transit Time destacados pelos entrevistados. São efetivamente os critérios que auxiliam o embarcador na tomada de decisão para a contratação do conjunto transportador/modo de transporte 
- figura 5 .

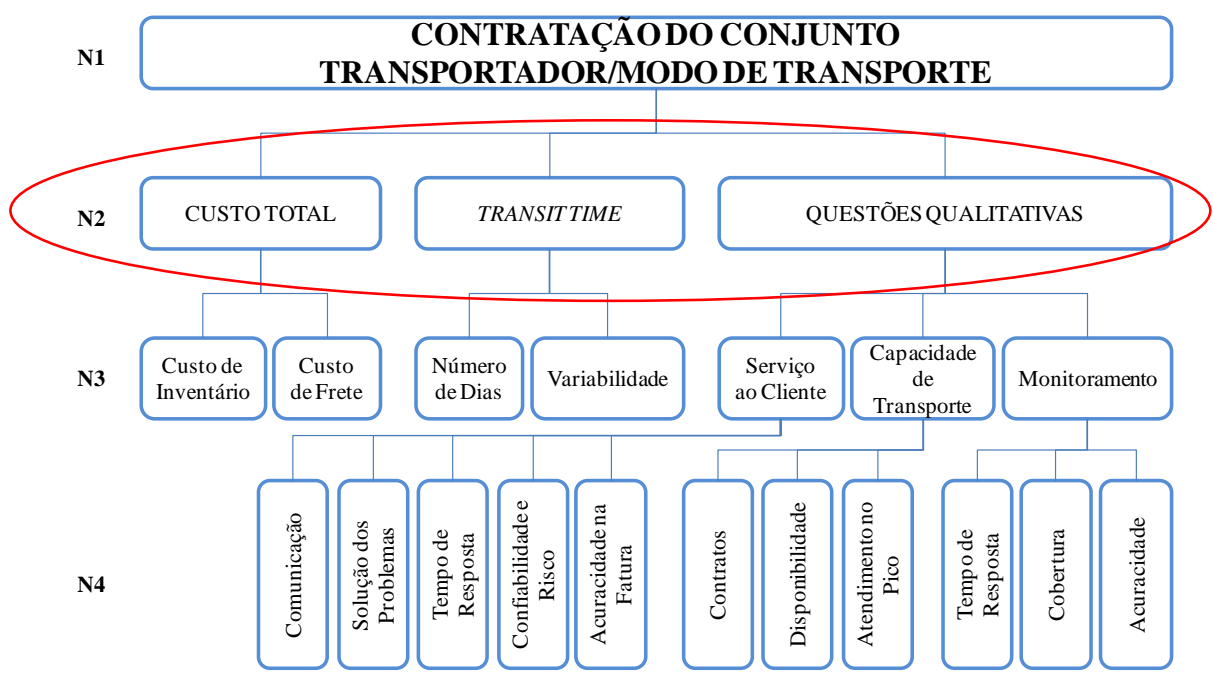

Figura 5- Árvore hierárquica simples de 04 níveis.

\subsection{Comparativo - caso empresa $1 \times$ caso empresa 2}

Considerando o estado ideal onde todos os modos de transporte estão disponíveis ao embarcador para seleção, e também condições normais de operação, ambos entrevistados concordaram que a seguinte estrutura ilustra as opções preferenciais para a contratação do conjunto transportador/modo de transporte:

$$
\begin{aligned}
& 1^{\text {a }} \text { opção - modo hidroviário; } \\
& 2^{\mathrm{a}} \text { opção - modo ferroviário; } \\
& 3^{\mathrm{a}} \text { opção - modo rodoviário. }
\end{aligned}
$$

A justificativa se baseia, efetivamente, na questão do custo total de frete, que é o critério principal destacado por ambos os embarcadores. Daí a opção principal pelo modo hidroviário, seguido do ferroviário, tendo por último, o modo rodoviário. A tabela 8 permite uma análise comparativa entre as visões do embarcador da Empresa 1 e da Empresa 2, na contratação do conjunto transportador / modo de transporte.

Tabela 8- Comparativo do resultado dos casos Empresa 1 e Empresa 2.

\begin{tabular}{|l|r|r|r|r|}
\hline \multicolumn{5}{|c|}{ EMPRESA 1 } \\
\hline Alternativa / Modo Critério & RODOVIÁRIO & FERROVIÁRIO & HIDROVIÁRIO & Pr. Critérios \\
\hline Custo Total & 0,069 & 0,310 & 0,621 & 0,652 \\
\hline Transit Time & 0,600 & 0,200 & 0,200 & 0,217 \\
\hline QuestõeQualitativas & 0,652 & 0,130 & 0,217 & 0,130 \\
\hline \multicolumn{7}{|c|}{ Priodade Final } & $\mathbf{0 , 2 6 0}$ & $\mathbf{0 , 2 6 3}$ & $\mathbf{0 , 4 7 7}$ & $\cdots$ \\
\hline \multicolumn{7}{|c|}{ EMPRESA 2 } \\
\hline Alternativa / Modo Critério & RODOVIÁRIO & FERROVIÁRIO & HIDROVIÁRIO & Pr. Critérios \\
\hline Custo Total & 0,077 & 0,231 & 0,692 & $\downarrow$ \\
\hline Transit Time & 0,652 & 0,217 & 0,130 & $\mathbf{0 , 5 4 5}$ \\
\hline Questões Qualitativas & 0,600 & 0,200 & 0,200 & $\mathbf{0 , 2 7 3}$ \\
\hline Prioridade Final & $\mathbf{0 , 3 2 9}$ & $\downarrow \mathbf{0 , 2 2 2}$ & $\downarrow \mathbf{0 , 4 5 0}$ & $\mathbf{0 , 1 8 2}$ \\
\hline
\end{tabular}

A prioridade final da alternativa rodoviário aumentou de 0,260 para 0,329 , como apresenta anteriormente a tabela 8, ilustra a valorização do modo de transporte rodoviário. O caso da Empresa 1, apresentar a alternativa modo rodoviário como segunda opção, divergindo do caso da Empresa 1, 
baseia-se no fato do embarcador da Empresa 2 ter valorizado os critérios de transit time e questões qualitativas, aproximado-as do critério custo total de frete, ou seja, reduzindo as notas na escala de Saaty, como pode ser observado a seguir na tabela 9, contribuindo para o aumento de suas respectivas prioridades $-p_{r}-$ no modo rodoviário, e justificando o aumento da prioridade final do modo rodoviário na tabela 8 .

Tabela 9- Comparativo dos critérios principais dos casos da Empresa 1 e Empresa 2

\begin{tabular}{|l|c|c|c|}
\hline \multicolumn{4}{|c|}{ EMPRESA 1 } \\
\hline CRITÉRIO & Custo Total & Transit Time & Questões Qualitativas \\
\hline Custo Total & 1 & 3 & 5 \\
\hline \multicolumn{4}{|c|}{ EMPRESA 2 } \\
\hline CRITÉRIO & Custo Total & Transit Time & Questões Qualitativas \\
\hline Custo Total & 1 & $2 \downarrow$ & $3 \downarrow$ \\
\hline
\end{tabular}

Contribuíram também para a colocação da alternativa modo rodoviário em segundo lugar a desvalorização do critério custo total do modo frete ferroviário, alterando na tabela 10, a escala Saaty de 2 para 3 em relação à avaliação do embarcador da Empresa 1, destacando-o como ainda mais caro que o custo de frete do modo hidroviário e também, a desvalorização do critério transit time do modo hidroviário, alterando na tabela 10 a escala Saaty de 3 para 5 em relação à avaliação do embarcador da Empresa 1.

Tabela 10- Comparativo das Tabelas Saaty dos casos das empresas 1 e 2

\begin{tabular}{|l|c|c|c|}
\hline \multicolumn{5}{|c|}{ EMPRESA 1 } \\
\hline Custo Total & RODOVIÁRIO & FERROVIÁRIO & HIDROVIÁRIO \\
\hline HIDROVIÁRIO & 9 & 2 & 1 \\
\hline Transit Time & RODOVIÁRIO & FERROVIÁRIO & HIDROVIÁRIO \\
\hline RODOVIÁRIO & 1 & 3 & 3 \\
\hline Questões Qualitativas & RODOVIÁRIO & FERROVIÁRIO & HIDROVIÁRIO \\
\hline RODOVIÁRIO & 1 & 5 & 3 \\
\hline \multicolumn{4}{|c|}{ EMPRESA 2 } \\
\hline Custo Total & RODOVIÁRIO & FERROVIÁRIO & HIDROVIÁRIO \\
\hline HIDROVIÁRIO & 9 & 3 & 1 \\
\hline Transit Time & RODOVIÁRIO & FERROVIÁRIO & HIDROVIÁRIO \\
\hline RODOVIÁRIO & 1 & 3 & 5 \\
\hline Questões Qualitativas & RODOVIÁRIO & FERROVIÁRIO & HIDROVIÁRIO \\
\hline RODOVIÁRIO & 1 & 3 & 3 \\
\hline
\end{tabular}

Desta forma, fica estabelecida tanto no caso da Empresa 1 quanto da Empresa 2, a importância destacada pelos respectivos embarcadores entrevistados que o critério Custo Total é o de maior relevância, destacados por eles, em virtude do seu peso financeiro em toda a operação para escoamento da carga.

\section{CONCLUSÃO}

As rodovias, ferrovias e hidrovias devidamente estruturadas são necessárias para suportar logisticamente toda a cadeia de suprimentos do agronegócio das regiões de plantio às plantas de produção e aos mercados consumidores. Garantir que a cadeia de suprimentos do agronegócio opere em perfeita ordem é um desafio, no qual as bacias hidrográficas são extensas e pouco aproveitadas, 
as ferrovias possuem limitações operacionais e o modo rodoviário, o mais utilizado, carece de rodovias em boas condições de conservação.

Estes e outros diversos fatores contribuem de forma direta e/ou indireta para o sucesso do setor. E o conjunto transportador / modo de transporte da correta seleção e contratação deste conjunto evidencia sua importância e justifica a necessidade da efetiva identificação e classificação dos critérios que melhor auxiliam e orientam os embarcadores da área de logística das empresas do agronegócio brasileiro para o escoamento da carga.

A proposta de identificar e avaliar os critérios efetivamente utilizados na tomada de decisão da contratação deste conjunto transportador / modo de transporte, foi contemplada com entrevistas realizadas nas duas principais empresas do agronegócio do mercado brasileiro. Mas na contratação do conjunto transportador / modo de transporte não há um modelo definido que auxilie na avaliação e seleção do conjunto. Isto evidencia a necessidade de suportar esta ação com modelo e ferramental que auxilie o embarcador, tomador de decisão, a contratar o conjunto transportador / modo de transporte adequado a atender a necessidade de escoamento da carga agrícola.

Como resultado, percebe-se que o método AHP é consistente no apoio a decisão para a avaliação dos critérios de escolha dos modos de transporte. No estudo, foi considerado o estado ideal, no qual os modais estão disponíveis ao embarcador para seleção, em condições normais de operação, tem-se que o principal critério é o custo total. O segundo critério em importância, não considerando a urgência do embarque da carga, é o tempo total de trânsito percorrido entre a origem e o destino, desconsiderando ações de carga e descarga, com a garantia de cumprimento do prazo. Por fim, o critério questões qualitativas dos demais quesitos que influenciam a escolha transportador e modais.

Assim, para maximizar a performance da proposta seria necessário o desenvolvimento de corredores de exportação, estruturados a partir da região Centro-Oeste, maior produtora, para facilitar o escoamento da produção de forma rápida e eficiente, garantindo maior competitividade e capacidade de atendimento às demandas no momento em que são solicitadas. O desenvolvimento do projeto dos corredores logísticos possibilita que haja incremento na atividade de produção de grãos, pois aumenta a margem de lucro de todo o processo devido à redução de custos relativos ao transporte como a redução de perdas, maior agilidade e rapidez no transporte e distribuição das cargas, aumentando a confiança do produtor, operador logístico e cliente final.

\section{REFERENCIAS}

AHARONOVITZ, M. C. S.; VIEIRA, J. G. V. Proposta de modelo multicritério para seleção de fornecedores de serviços logísticos. Revista GEPROS, v. 9, n. 1, p. 9, 2014.

ALVES, J. R. X.; ALVES, J. M. Definição de localidade para instalação industrial com o apoio do método de análise hierárquica (AHP). Production Journal, v. 25, n. 1, p. 13-26, 2015.

ALVES, J. N. et al. CARACTERIZAÇÃO DO PERFIL LOGÍSTICO DE ESCOAMENTO DE GRÃOS DE UMA CIDADE DO INTERIOR DO RIO GRANDE DO SUL. Revista Univap, v. 18, n. 32, p. 173-189, 2012.

ANTF - Associação Nacional dos Transportadores Ferroviários. Disponível em: 〈http://www.antf.org.br $\rangle$. Acesso em 15 de outubro de 2014.

BANCO DE INFORMAÇÕES E MAPAS DE TRANSPORTES. Transporte Ferroviário e Hidroviário do Brasil. Brasília, Ministério dos Transportes. Disponível em: <http://www2.transportes.gov.br/bit/01-inicial/index.html>. Acesso em 05 de junho de 2015.

BOZOKY, M. J. et al. ANÁLISE DO MODAL FERROVIÁRIO NO TRANSPORTE DE SOJA DO CENTRO OESTE AOS PORTOS. INOVAE-Journal of Engineering and Technology Innovation, v. 2, n. 1, p. 50-61, 2014. 
BRAGA, V.; CASTILLO, R. Tipologia e topologia de nós logísticos no território brasileiro: uma análise dos terminais ferroviários e das plataformas multimodais. Boletim Campineiro de Geografia, v. 3, n. 2, p. 235-258, 2014.

BRANCO, J. E. H. et al. Otimização Logística para o Transporte Multimodal de Safras Agrícolas no Brasil com Foco no Corredor Nordeste. REN. Revista econômica do nordeste, v. 43, n. 1, p. 67-92, 2012.

BRAVO, J. J.; VIDAL, C. J. Freight transportation function in supply chain optimization models: A critical review of recent trends. Expert Systems with Applications, v. 40, n. 17, p. 6742-6757, 2013.

Companhia Nacional de Abastecimento, Acompanhamento da safra brasileira de grãos. v. 2 - Safra 2014/15, n. 8. Brasília: CONAB, $2015 . \quad$ Disponível em: <http://www.conab.gov.br/OlalaCMS/uploads/arquivos/15_05_13_08_46_55_boletim_graos_maio_2015.pdf>. Acessado em 25 de maio de 2015.

CORREA, V. H. C.; RAMOS, P. A precariedade do transporte rodoviário brasileiro para o escoamento da produção de soja do Centro-Oeste: situação e perspectivas. Revista de Economia e Sociologia Rural, v. 48, n. 2, p. 447-472, 2010.

DA SILVA, M. P.; MARUJO, L. G. Análise de modelo intermodal para escoamento da produção da soja no centro oeste brasileiro. Journal of Transport Literature, v. 6, n. 3, p. 90-106, 2012.

DE LIMA, M. R. T. R.; BUENO, A. P. Mobilidade urbana em planos diretores: análise sintática da malha viária da área conurbada de Florianópolis. Anais: Encontros Nacionais da ANPUR, v. 14, 2013.

DE SOUZA, L. L. A Logística da Soja na Fronteira Agrícola Norte e Nordeste. Dissertação apresentada para obtenção do título de pós graduação em Logística Agroindustrial, Universidade de São Paulo, Escola Superior de Agricultura "Luiz de Queiroz", Piracicaba, 2012.

DEMIR, E. et al. A selected review on the negative externalities of the freight transportation: Modeling and pricing. Transportation Research Part E: Logistics and Transportation Review, v. 77, p. 95-114, 2015.

DULAC, J. Global land transport infrastructure requirements. Paris: International Energy Agency, v. 20, p. 2014, 2013. Disponível em: <http://www. iea. org/publications/freepublications/publication/TransportInfrastructureInsights_FINAL_WEB.pdf.> Acesso em 29 de maio de 2015.

GRANEMANN, S.; FIGUEIREDO, A. Logística Aplicada À Exportação-Instrumento De Competitividade. Revista Brasileira de Economia de Empresas, v. 1, n. 1, 2013.

IBGE - Instituto Brasileiro de Geografia e Estatística. Estatísticas 2013. Disponível em: <http://www.ibge.gov.br/home/geociencias/cartografia/default_territ_area.shtm>. Acesso em: 05 de junho de 2015.

KAKAR, A. K.; HALE, J. E.; HALE, D. P. Lean Software Development: Evaluating Techniques for Parsimonious Feature Selection of Evolving Information Systems Products. In: 8th Pre-ICIS International Research Workshop on Information Technology Project Management (IRWITPM 2013). 2013. p. 71-87.

MESA-ARANGO, R.; UKKUSURI, S. V. Benefits of in-vehicle consolidation in less than truckload freight transportation operations. Transportation Research Part E: Logistics and Transportation Review, v. 60, p. 113 125,2013

MOREIRA, E. F. A. et al. Previsão de área destinada à produção de soja via análise de séries temporais. Matemática e Estatística em Foco, v. 1, n. 2, 2013.

MOREIRA NETO, J. G. O mercado de exportação de soja e os portos brasileiros. Brasília: Agência de Transportes Aquaviários, $2015 . \quad$ Disponível em: <http://www.antaq.gov.br/portal/pdf/Artigos/20150123_Artigo_Jose_Goncalves_Moreira_Neto.pdf>. Acessado em 25 de maio de 2015.

MOTA, C. C. de P.; CERQUEIRA, J. da S.; REZENDE, A. A. de. Participação da Produção da Soja na Balança Comercial: Uma Análise Comparativa a partir da Produção do Estado do Mato Grosso, no Período de 2002 a 2012. Revista de Estudos Sociais, v. 15, n. 29, p. 109-125, 2014.

QUADROS, S. G. R.; NASSI, C. D. An evaluation on the criteria to prioritize transportation infrastructure investments in Brazil. Transport Policy, v. 40, p. 8-16, 2015.

SALIN, D. L. Soybean transportation guide: Brazil 2013. Washington: United States Department of Agriculture, Agricultural $\quad$ Marketing $\quad$ Service, $2014 . \quad$ Disponível em: <http://www.ams.usda.gov/AMSv1.0/getfile?dDocName=STELPRDC5108087>. Acesso em 25 de maio de 2015. 
SANTOS, A. B.; SPROESSER, R. L.; MARTINS, R. S. Caracterização e Avaliação da Eficiência dos Terminais Intermodais do Corredor Logístico de Grãos Centro-Leste. Revista ADM. MADE, v. 17, n. 1, p. 1-23, 2013.

SARAIVA, P. L. O.; MAEHLER, A. E. Transporte hidroviário: estudo de vantagens e desvantagens em relação a outros modais de transporte no sul do Brasil. Anais: SIMPOI, v. 16, 2013.

SOUZA, C. D. R. et al. Inventory of conventional air pollutants emissions from road transportation for the state of Rio de Janeiro. Energy Policy, v. 53, p. 125-135, 2013.

STEADIESEIFI, M. et al. Multimodal freight transportation planning: A literature review. European Journal of Operational Research, v. 233, n. 1, p. 1-15, 2014.

TINOCO, R. de M.; LEAL, J. E.; ARAUJO, L. C. de A. Seleção do portfolio de projetos de logística em uma empresa da indústria de óleo e gás. ANPET, v. 27, 2013.

VILAÇA, R. Infraestrutura e competitividade logística. Revista Tecnologística, n. 201, p. 98-101, agosto de 2012.

WALTER, O. M. F. C.; TUBINO, D. F. Assessment methods of lean manufacturing: literature review and classification. Gestão \& Produção, v. 20, n. 1, p. 23-45, 2013.

WANG, Z.; LU, M.. An empirical study of direct rebound effect for road freight transport in China. Applied Energy, v. 133, p. 274-281, 2014.

WANKE, P.; BARROS, C. P.; FIGUEIREDO, O. Measuring efficiency improvement in Brazilian trucking: A Distance Friction Minimization approach with fixed factors. Measurement, v. 54, p. 166-177, 2014. 